\title{
Soft tissue coverage of the knee joint following burns
}

\author{
Chenicheri Balakrishnan MD, Thomas L Flanagan MD, Justin D Klein MD, \\ Venkata S Erella MD, Manmit S Saini MD
}

C Balakrishnan, TL Flanagan, JD Klein, VS Erella, MS Saini. Soft tissue coverage of the knee joint following burns. Can J Plast Surg 2006;14(3):163-166.

Full-thickness burns around the knee joint are usually associated with exposure of bone, tendon or ligaments. Following excision of the deep burns, there is no viable wound bed to which skin grafts can be applied. Although vacuum-assisted closure has been used to encourage granulation tissue, exposure of the tendons and ligaments following excision usually requires muscle flaps or fasciocutaneous flaps.

\section{Le comblement des tissus mous du genou après une brûlure}

\begin{abstract}
Les brûlures du troisième degré au genou sont généralement associées à une exposition des os, des tendons ou des ligaments. Après l'exérèse des brûlures profondes, il ne reste plus de lit récepteur de greffons de peau. Même si on a recours à la cicatrisation par pression négative pour favoriser la formation de tissu de granulation, l'exposition des tendons et des ligaments à la suite de l'exérèse des tissus nécrosés nécessite généralement la pose de lambeaux musculaires ou de lambeaux fascio-cutanés.
\end{abstract}

Key Words: Burns; Knee joint; Soft tissue coverage

Soft tissue defects around the knee joint may occur following $\checkmark$ surgical procedures for joint problems, excision of tumours, trauma or deep burns. These wounds, with exposed tendons, joint and hardware, present a challenge to the reconstructing surgeon. Full-thickness burns of the lower extremity, involving the knee joint, present a difficult problem for the reconstructing surgeon. Even in cases where a skin graft can be placed over a granulating bed, this usually results in an unstable coverage with repeated breakdown. Skin grafts around the knee are notorious for scar contractures. An exposed knee joint in a burn patient may lead to septic arthritis of the joint. As in exposed knee arthroplasty, adequate soft tissue coverage is necessary for successful reconstruction in these patients. We report our experience with three patients who presented to us with deep burns involving their knee joint as part of their thermal injury. Two patients were treated with a fasciocutaneous flap and the other patient was treated with a lateral head of gastrocnemius muscle flap. All flaps provided stable coverage and resulted in full function of their knee joints.

\section{CASE PRESENTATIONS}

Case 1

A 24-year-old man sustained a circular contact burn to the knee from a motorcycle exhaust pipe following an accident (Figure 1A), in addition to a closed head injury. Upon debridement, the burn was found to involve the periosteum of the patella. He underwent bipedicled fasciocutaneous flap coverage of the patella (Figure 1B) with skin grafting of the lateral defect (Figure 1C).

\section{Case 2}

A 53-year-old man sustained flame burns to both lower extremities following a house fire. Over $60 \%$ of his total body surface area was burned; in addition, the patient sustained a severe inhalation injury. He underwent early excision with allografting of the lower extremity, and skin grafting of the upper extremity. His lower extremity burns were deep, involving the periosteum covering the tibia and patella (Figure 2A). At the time of skin grafting, a bipedicled fasciocutaneous flap was elevated to cover the exposed patella (Figure 2B). The knee was splinted following skin grafting, and the wounds healed well, resulting in stable coverage and good function (Figure 2C).

\section{Case 3}

A 30-year-old man sustained burns to the knee and lower extremity following a motor vehicle accident. His knee joint had been reconstructed in the past for a cruciate ligament injury. He underwent excision and was referred for coverage because the patella and the lateral ligament of the knee were exposed (Figure 3A). He underwent reconstruction with a lateral gastrocnemius flap (Figure 3B) followed by skin grafting (Figure 3C). The knee joint was immobilized for two weeks. He underwent physical therapy with a hinged brace and has obtained full function of the knee at six weeks (Figures 3D and 3E).

\section{DISCUSSION}

Reconstruction of the soft tissue defects around the knee joint should be aimed at obtaining adequate functional and aesthetic result with minimal donor site morbidity. Early aseptic closure of the knee joint is important for preservation of function. Soft tissue defects occur around the knee joint from wound break down following surgery, trauma and deep burns, and following release of burn scar contracture. Deep burns crossing the knee joint are associated with contractures 

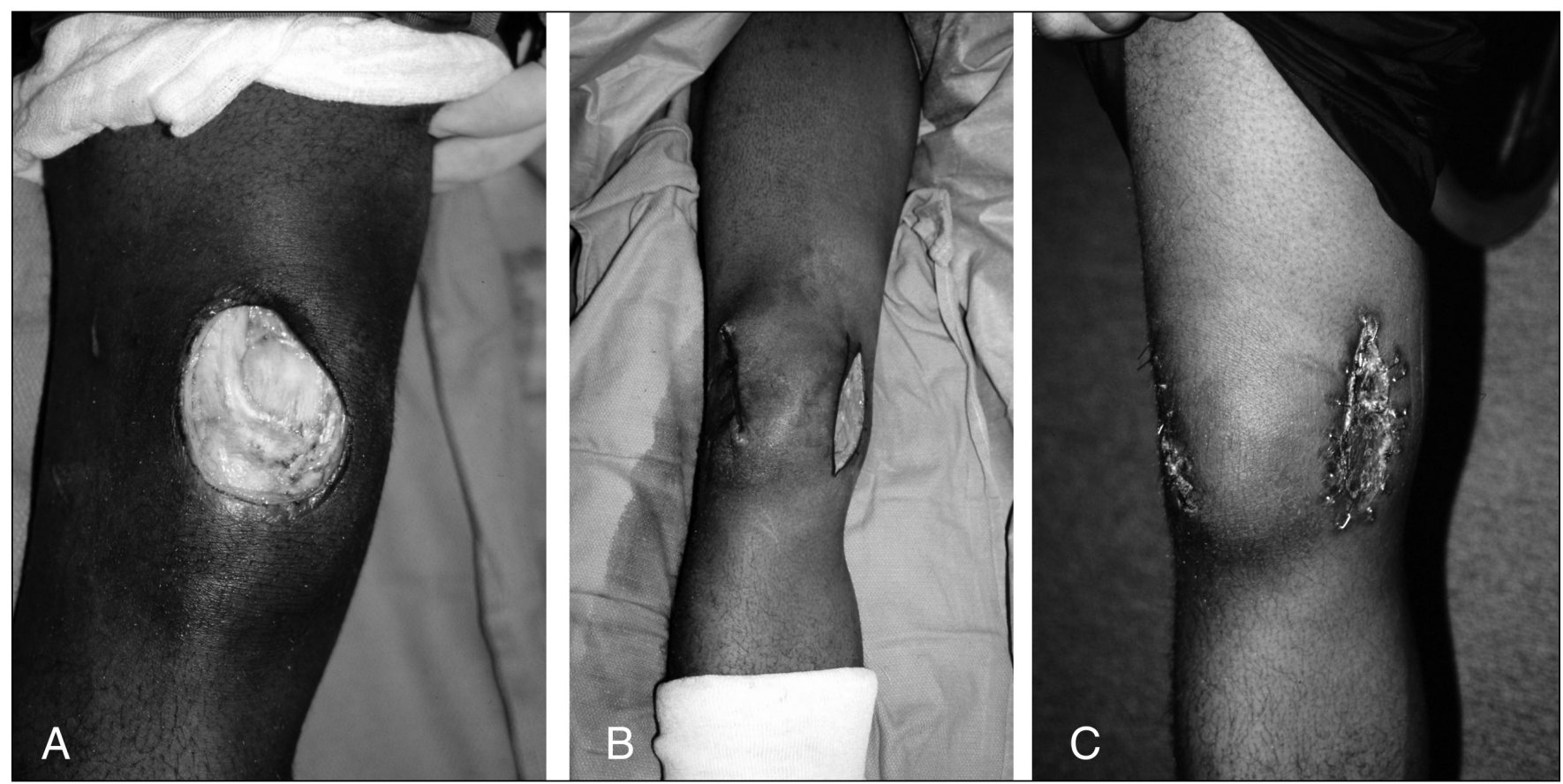

Figure 1) Case 1. A Burns to knee with exposed patella; B Bipedicled flap; C Healed flap with skin graft over the lateral knee
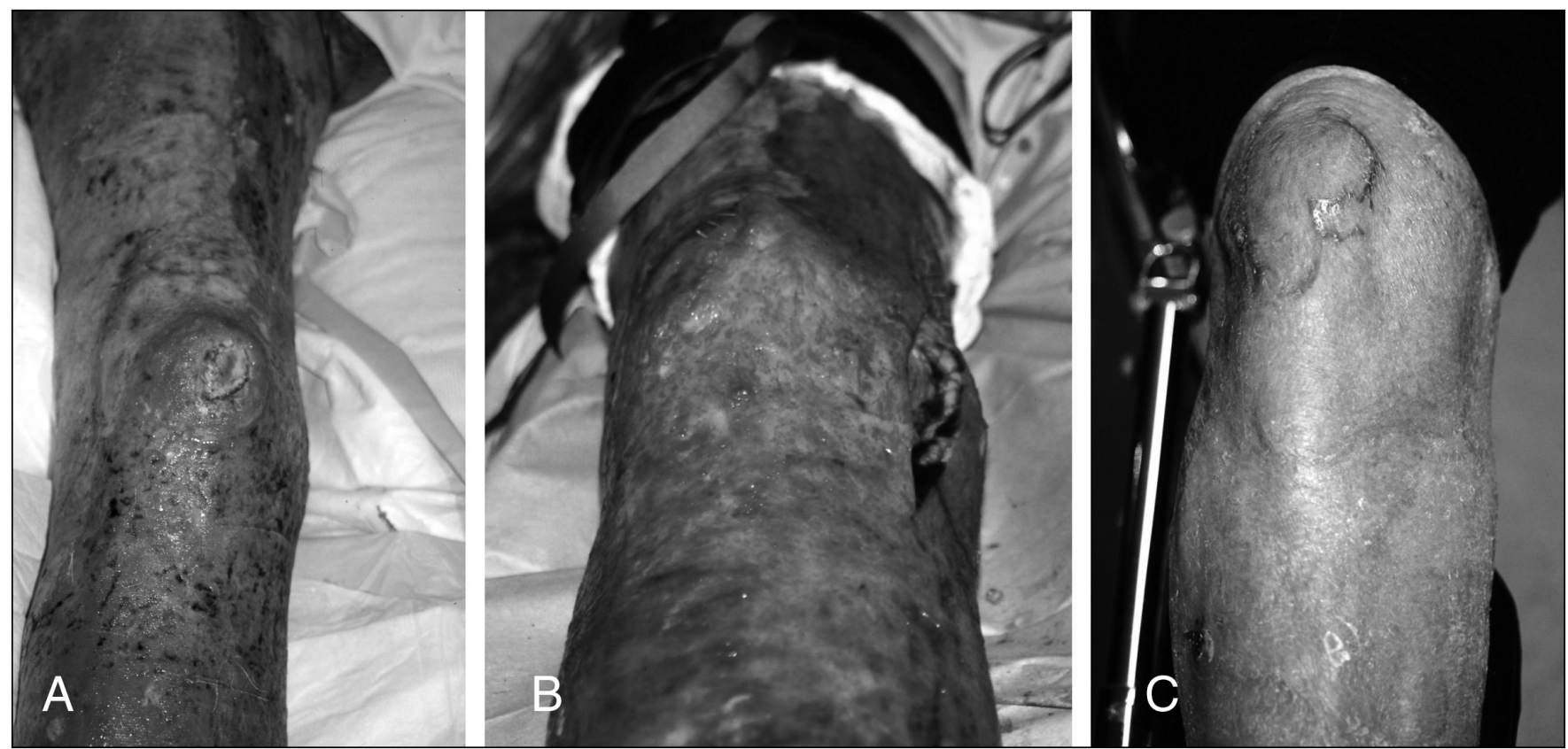

Figure 2) Case 2. A Burns of the knee; B Fasciocutaneous flap to close the exposed patella; C Following skin grafting

and destruction of the patellar tendon. The reconstruction of soft tissue defects around the knee joint presents a difficult challenge to the reconstructive surgeon, especially in burn patients. The various reconstruction options depend on the location, size and depth of defect relative to the knee joint. However, in burn patients, the burn injury to the knee usually accompanies burns to the lower leg. The aim of treatment of deep burns around the knee is to obtain stable healed wounds, allowing pain-free mobility of the joint. During excision of deep burns around the knee joint, there is significant risk of violating the joint. An open joint usually results if a capsule is exposed. Therefore, a viable joint should be covered with soft tissue as soon as possible to prevent septic complications of the joint. When bone is devoid of periosteum, this should be covered with soft tissue or, as practiced in the past, granulation tissue growth could be stimulated by making fenestrations into the marrow cavity. Although split-thickness skin grafts can be applied to these granulating beds, the affected skeletal structures often lack mechanical stability. 

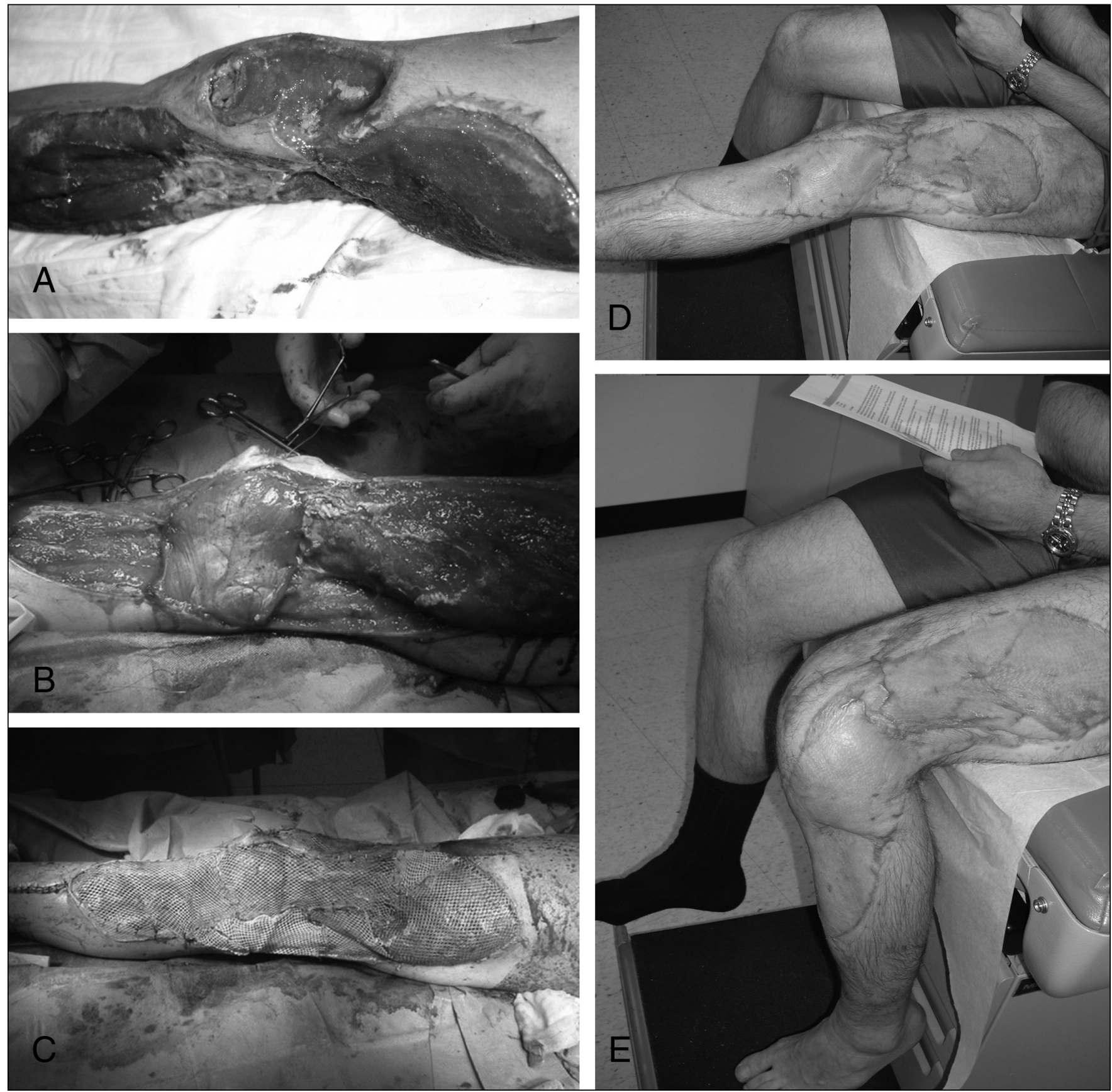

Figure 3) Case 3. A Burns following debridement with exposed knee joint; B Gastrocnemius flap to cover the joint; C Following skin grafting over the muscle flap; D, E Healed wound with full knee movements

Management of soft tissue defects around the knee depends on the extent of tissue damage, the size of defect and the feasibility of the wound bed to accept a skin graft. For extensive destruction of the skin alone, debridement, followed by skin grafting, is the most common method of treatment. The vacuumassisted closure technique has facilitated a good granulating bed for application of skin grafts in some cases. The continuous subatmospheric suction greatly reduces the amount of tissue edema, diminishing the circumference of the extremity and thus decreasing the surface area of the wound (1). When the knee joint is exposed from soft tissue loss, flap coverage is required for joint and, sometimes, limb salvage. The availability of local flap coverage is limited in some patients due to surrounding tissue necrosis and, therefore, the use of free tissue transfer plays an important role in limb salvage (2,3). The gastrocnemius muscle flap, usually the medial half, has been used for coverage of exposed or infected knee prostheses. The gastrocnemius muscle flap provides a well-vascularized tissue for retaining the exposed prosthesis or for reimplantation $(4,5)$. To provide muscle bulk with reliable vascular supply, the distally based prefabricated sartorius muscle flap has been used as a two-stage technique (6) with good results. Aggressive management with early excision of all nonviable tissue, followed by soft tissue coverage of the exposed bone and ligaments using 
local flaps, provide the best outcome. Reports related to reconstruction of the soft tissue defects of the knee following deep burns generally focus on the management of post-burn contractures (7). In an acute burn, the management should be on the same lines as that of postsurgical dehiscence. Immediate coverage of open knee and ankle joints with fascial flap and Biobrane (Bertek Pharmaceuticals Inc, USA) for temporary coverage has been reported (8).

\section{REFERENCES}

1. DeFranzo AJ, Argenta LC, Marks MW, et al. The use of vacuumassisted closure therapy for treatment of lower-extremity wounds with exposed bone. Plast Reconstr Surg 2001;108:1184-91.

2. Pu LL, Thomson JG. Salvage of the exposed irradiated knee joint with free tissue transfer. Ann Plast Surg 2000;44:334-9.

3. Yuen JC, Zhou AT. Free flap coverage for knee slavage. Ann Plast Surg 1996;37:158-66.

4. Gerwin M, Rothaus KO, Windsor RF, Brause BD, Insall JN. Gastrocnemius muscle flap coverage of exposed or infected knee prosthesis. Clin Orthop Relat Res 1993;286:64-70.

5. Greenberg B, LaRossa D, Lotke PA, Murphy JB, Noone RB.
In the present study, coverage was accomplished in two patients using the fasciocutaneous flap as soon as it was realized that the periosteum was lost over the patella. The third patient presented following excision and vacuum-assisted closure therapy after it was realized that the lateral ligament of knee joint was involved. He was treated with the gastrocnemius muscle flap. All healed without complications and with good functional outcome.

Salvage of jeopardized total-knee prosthesis: The role of gastrocnemius muscle flap. Plast Reconstr Surg 1989;83:85-9, 97-9.

6. Hong JP, Lee HB, Chung YK, Kim SW, Tark KC. Coverage of difficult wounds around the knee joint with prefabricated, distally based sartorius muscle flaps. Ann Plast Surg 2003;50:484-90.

7. Chowdri NA, Darzi MA. Z-lengthening and gastrocnemius muscle flap in the management of severe post burn contracture of the knee. J Trauma 1998;45:127-32.

8. Frame JD, Taweepoke P, Moieman N, Rylah L. Immediate fascial flap reconstruction of joints and use of Biobrane in the burned limb. Burns 1990;16:381-4. 